\title{
INVESTIGAÇÃO COMPUTACIONAL DO IMPACTO DOS PARÂMETROS TERMOMECÂNICOS NA MICROESTRUTURA DE UM AÇO MICROLIGADO AO NIÓBIO DURANTE A LTQ *
}

\author{
Melina Gamis da Silva ${ }^{1}$ \\ Felipe Monteiro Moraes de Moura Bastos ${ }^{2}$ \\ Carlos Roberto Guinancio Carvalho ${ }^{3}$ \\ Marcelo Arantes Rebellato ${ }^{4}$ \\ Otávio Luiz Cardoso de Souza ${ }^{5}$ \\ Christien Guisard Hauegen ${ }^{4}$ \\ Sidney Ferreira da Silva ${ }^{7}$
}

\section{Resumo}

Em um trabalho anterior [1], as temperaturas de processamento aplicadas na laminação de tiras a quente, LTQ, da CSN foram investigados para algumas classes de aços microligados ao $\mathrm{Nb}$. Os resultados deste trabalho mostraram a possibilidade da redução da temperatura de reaquecimento utilizada para esses aços refletindo em possibilidades de melhoria de produtividade. No trabalho atual, o impacto dessas mudanças na microestrutura obtida de LTQ foi investigado com mais profundidade, utilizando um software desenvolvido para prever a evolução da microestrutura em termos das frações recristalizadas, das distribuições de tamanhos de grãos e do comportamento das tensões médias de escoamento, TME.

Palavras-chave: Aços microligados ao Nb; Modelagem matemática; Distribuição de grãos; Laminação de tiras a quente.

\section{COMPUTATIONAL INVESTIGATION OF THE IMPACT OF THERMOMECHANICAL PARAMETERS IN THE MICROSTRUCTURE OF A STEEL MICROALLOYED THE NIOBIUM DURING THE LTQ}

\begin{abstract}
In a previous work ${ }^{[1]}$, the processing temperatures applied in the hot strip mill rolling process, LTQ, of CSN were investigated for some classes of steelsmicroalloyed to Niobium. The results of this work showed the possibility of reduction of the reheating temperature used for these steels, reflecting in productivity improvements. In the current work, the impact of these changes on the microstructure obtained fromthe LTQprocess was investigated in more depth, using a software developed to predict the evolution of the microstructure in terms of the recrystallized fractions, the grain size distributions and the behavior of the mean flow stresses, TME.

Keywords: Nb microalloyed steels; Computational Model; Distribution of grains; Hot strip rolling.

\footnotetext{
Engenheira Metalúrgica, Mestre,Companhia Siderúrgica Nacional, Volta Redonda, RJ, Brasil.

Engenheiro Metalúrgico, Consultor, Eurosport, São Paulo, SP, Brasil.

Engenheiro Metalúrgico, Mestre, Companhia Siderúrgica Nacional, Volta Redonda, RJ, Brasil.

Engenheiro Metalúrgico, Consultor, CBMM, São Paulo, SP, Brasil.

Engenheiro Metalúrgico, Companhia Siderúrgica Nacional, Volta Redonda, RJ, Brasil.

Engenheiro Metalúrgico, Mestre, Companhia Siderúrgica Nacional, Volta Redonda, RJ, Brasil.

Engenheiro Metalúrgico, Companhia Siderúrgica Nacional, Volta Redonda, RJ, Brasil.
} 


\section{INTRODUÇÃO}

Um balanço entre metalurgia e produtividade é a consideração mais importante em processos de laminação de tiras a quente, LTQ, de aços estruturais microligados. Neste âmbito, a aplicação de ferramentas virtuais que possibilitem o aprimoramento de processos industriais tem sido cada vez mais comum pela rapidez e pelos baixos custos envolvidos. Levando em conta essas considerações, a avaliação de possíveis melhorias foi a força motriz para esse trabalho.

Como primeira etapa do estudo da modelagem de um processo, os parâmetros termomecânicos que têm impacto direto na microestrutura da austenita obtida devem ser avaliados. Esses parâmetros são: as deformações aplicadas na laminação, as taxas de deformação, as temperaturas de reaquecimento da placa e de laminação e os intervalos de tempo entre passes. Em um trabalho anterior ${ }^{[1]}$, as temperaturas de reaquecimento e de deformação aplicadas na LTQ da CSN foram avaliadas para uma classe de aços microligados ao $\mathrm{Nb}$, e comparadas com as temperaturas críticas calculadas para este processo. Os resultados mostraram que, para a composição química considerada, a temperatura de reaquecimento poderia ser reduzida sem causar prejuízos à solubilização de $\mathrm{Nb}$.

No trabalho atual, o impacto da modificação da temperatura de reaquecimento, e assim das temperaturas de processamento, foi investigado com mais profundidade para a mesma classe de aços do trabalho anterior no processo de LTQ da CSN. Um modelo matemático foi desenvolvido para avaliar a evolução da microestrutura da austenita durante a LTQ. Os dados de entrada apresentados foram processados no modelo, e os resultados mostraram que as modificações realizadas não teriam impacto na microestrutura, que é descrita em termos das frações recristalizadas, das distribuições de tamanhos de grãos e das tensões médias de escoamento, TME, após cada passe de laminação. As microestruturas obtidas ao final da laminação também foram comparadas para as duas condições, mostrando que não houve alterações no produto final obtido.

\section{MODELO MATEMÁTICO}

Modelos matemáticos são ferramentas eficazes que permitem estudar processos industriais considerando condições iniciais e de contorno. No caso da laminação a quente de aços, o estudo da evolução do grão de austenita pode ser modelado permitindo compreender a influência dos parâmetros de processamento na microestrutura obtida do material. Para várias aplicações, modelos que têm como base a evolução do grão de austenita em termos do seu tamanho médio têm sido utilizados. Entretanto, quando requisitos mais particulares são necessários, como por exemplo o comportamento de tenacidade ou a homogeneidade da microestrutura, esses modelos não satisfazem as necessidades de compreensão e aprimoramento do processo estudado. Neste caso, o conhecimento do estado de distribuição de tamanhos de grão da austenita é necessário.

Considerando a necessidade de se estudar processos de laminação a quente onde tais requisitos são importantes, Uranga et al. ${ }^{[2]}$ descreveram uma metodologia que permite o desenvolvimento de um modelo capaz de prever a evolução da 
microestrutura durante a laminação a quente em termos da distribuição dos tamanhos de grão de austenita. A Figura 1 mostra o fluxograma que representa essa metodologia.

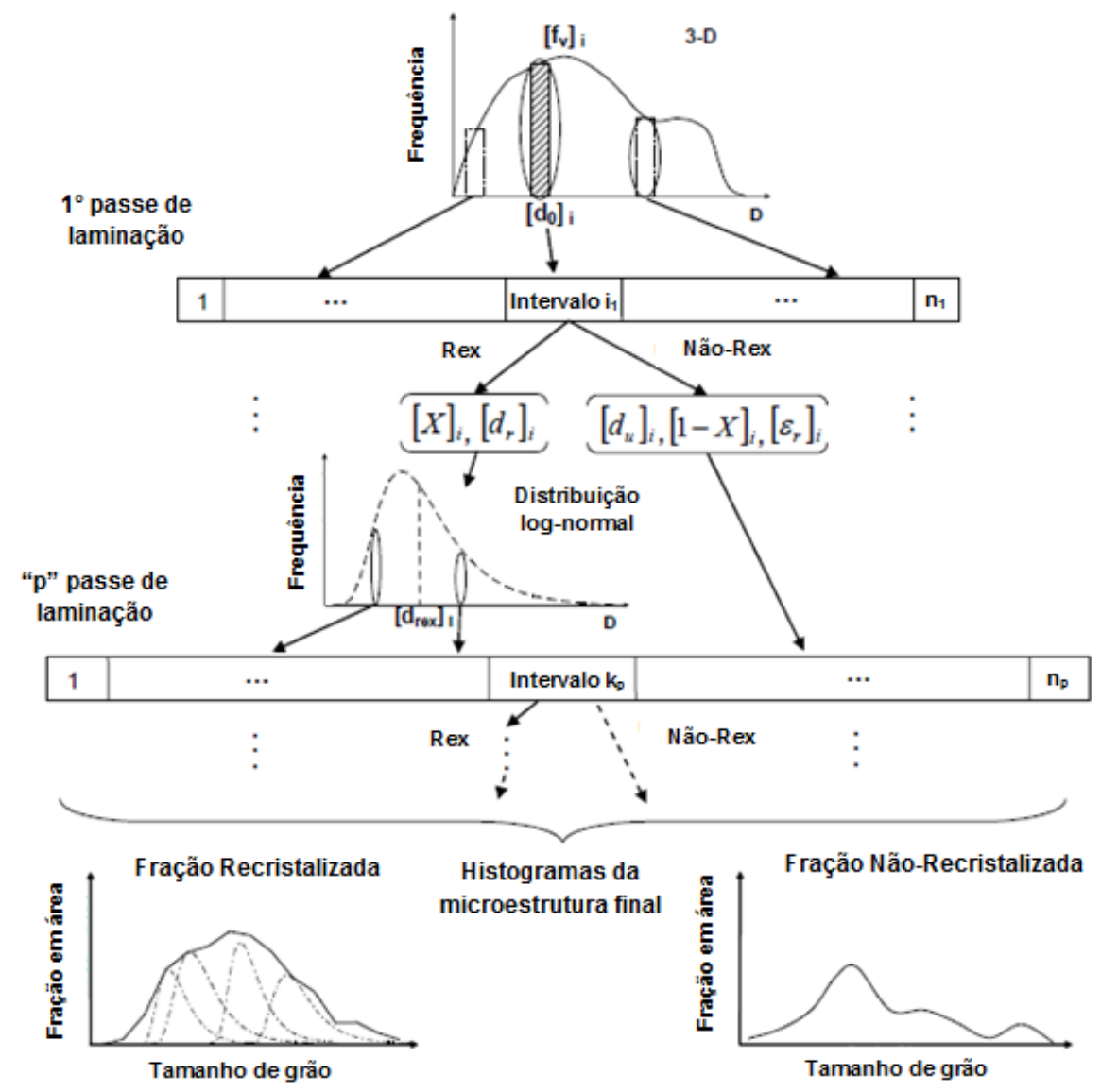

Figura 1.Estrutura do modelo de evolução da microestrutura considerando distribuição de tamanhos de grãos, proposto por Uranga et al. ${ }^{[2]}$.

Nesse modelo, uma distribuição inicial de tamanhos de grãos de austenita entrando do primeiro passe de laminação deve ser considerada. Essa distribuição é dividida em $n$ populações, geralmente de 11 a 15, cada uma caracterizada por um tamanho de grão representativo, [do]i, e sua fração volumétrica, $\left[f_{v}\right]$ i. Ao longo dos passes de laminação, cada população é acompanhada individualmente considerando as deformações, as taxas de deformação, as temperaturas de deformação e os intervalos de tempo entre passes aplicados. Ao final de cada passe, um histograma é gerado com informação da distribuição de grãos, recristalizados e nãorecristalizados, resultante ao final daquele passe, e a deformação acumulada na microestrutura.

Um software apresentado anteriormente [3] foi desenvolvido com base nessa metodologia para aplicação a processos de LTQ. As equações utilizadas para o desenvolvimento do modelo estão listadas nas referências [2] e [3]. A Figura 2 mostra o layout para a entrada de dados nesse modelo. 


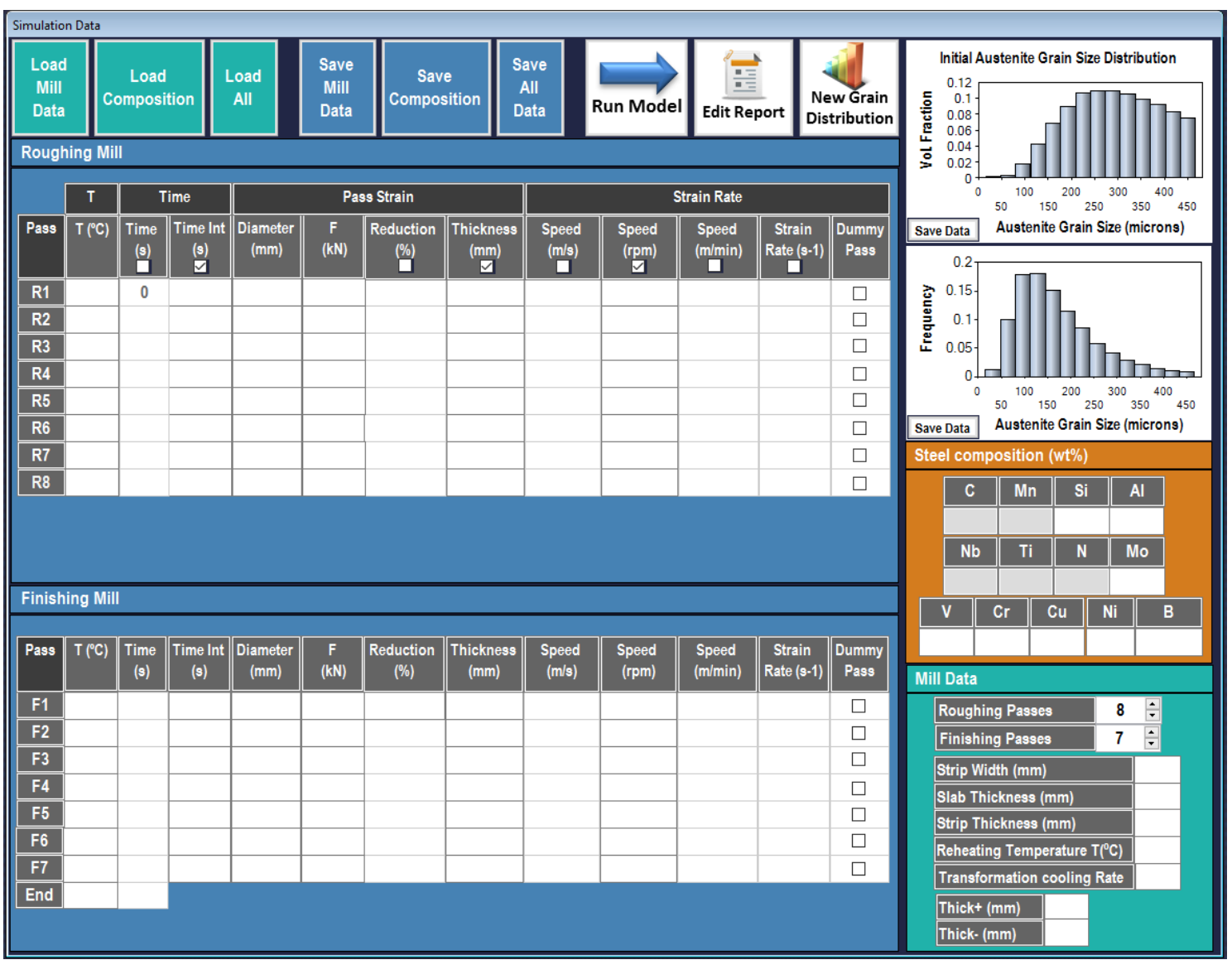

Figura 2.Tela inicial mostrando os dados necessários para rodar o modelo desenvolvido.

A tela mostrada na Figura 2 compreende os dados de entrada necessários para os cálculos e já comentados acima.

Além do estado da microestrutura final, o software desenvolvido calcula o comportamento da tensão média de escoamento do aço durante o processo. $O$ conhecimento da curva de TME é também uma ferramenta eficaz na análise do estado da microestrutura e dos mecanismos, de amaciamento e endurecimento, ocorrendo durante a laminação, e consequentemente, no produto final obtido ${ }^{[4]}$.

\section{PROCESSO DE LAMINAÇÃO DE TIRAS A QUENTE DA CSN}

O LTQ da CSN possui capacidade de fabricação de BQ's com espessuras nominais entre 1,2 e $12,7 \mathrm{~mm}$ e larguras entre 715 e $1575 \mathrm{~mm}$. No início do processo de laminação, as placas são reaquecidas em quatro fornos do tipo vigas caminhantes com capacidade de $250 \mathrm{t} / \mathrm{h}$. A temperatura média de desenfornamento é da ordem de $1200^{\circ} \mathrm{C}$.

A laminação de desbaste é realizada em trem desbastador com quatro cadeiras verticais (para laminação de bordas) e quatro cadeiras horizontais (para redução contínua da espessura). Nessa seção existem sistemas de descarepação por jatos de água de alta pressão acoplados às cadeiras (nas entradas de todos os passes), bem como sistemas de monitoramento e controle contínuo do processo de produção e temperatura. A redução total compreendida nessa etapa é distribuída entre cada 
passe do desbaste, de modo que a espessura final do esboço é de aproximadamente $35 \mathrm{~mm}$. A temperatura do material após esse etapa se encontra usualmente entre 1000 e $1100^{\circ} \mathrm{C}$, e pirômetros localizados no início e no final do desbaste permite estimar as temperaturas em cada passe.

A laminação de acabamento ocorre em trem acabador com sete cadeiras de laminação do tipo quádruo em tandem, com sistema de descarepação na entrada do trem e pirômetros que monitoram a temperatura continuamente. A velocidade de laminação depende do tipo de aço e dimensão produzida. As temperaturas de entrada e de saída do trem acabador também dependem do material que está sendo processado. As laminações de aços com Nb têm a particularidade de necessitar da prática de um tempo de espera entre as seções de desbaste e de acabamento, suficiente para se atingir a faixa de temperatura de precipitação de partículas com $\mathrm{Nb}$.

A seção de resfriamento acelerado localiza-se entre a última cadeira do trem acabador e as bobinadeiras. A temperatura nessa seção é reduzida pela aplicação, em ambas as faces da tira, de água em jatos tipo "laminar flow" através de 14 bancos de chuveiros. A temperatura final é especificada em função do tipo de material e das características metalúrgicas desejadas na bobina a quente. Ao final deste resfriamento, as tiras são bobinadas.

A Tabela 1 e a Tabela 2 mostram, respectivamente a composição química típida do aço estudado e as dimensões do produto e características de processamento.

Tabela 1. Composição química típica para aço estudado.

\begin{tabular}{|c|c|c|c|}
\hline Elemento & $\mathrm{C}$ & $\mathrm{Mn}$ & $\mathrm{Nb}$ \\
\hline Teor $[\%]$ & 0,10 & 0,53 & 0,024 \\
\hline
\end{tabular}

Tabela 2. Dados iniciais de processo

\begin{tabular}{|c|c|}
\hline Parâmetro & Valor \\
\hline Espessura da Placa $[\mathrm{mm}]$ & 257 \\
\hline Largura da Placa $[\mathrm{mm}]$ & 1200 \\
\hline Comprimento da Placa $[\mathrm{mm}]$ & 10500 \\
\hline Espessura da Tira $[\mathrm{mm}]$ & 6,00 \\
\hline Largura da Tira $[\mathrm{mm}]$ & 1200,0 \\
\hline Temperatura de Reaquecimento $\left[{ }^{\circ} \mathrm{C}\right]$ & 1200 \\
\hline $\mathrm{T}_{\mathrm{s}} \mathrm{AcC}\left[{ }^{\circ} \mathrm{C}\right]$ & 883 \\
\hline
\end{tabular}

Os dados de entrada apresentados na seção anterior foram inseridos no modelo. Os resultados previstos pela aplicação do modelo são apresentados a seguir.

\section{PREVISÕES DA MICROESTRUTURA E DISCUSSÕES}

\section{Condições originais}

Os resultados calculados pelo modelo considerando a condição original são mostrados na Figura 3, e compreendem:

- Fração recristalizada, Rex. Fraction;

- Fração não-recristalizada, No Rex., devido ao efeito de arraste do $\mathrm{Nb}$ em solução sólida, Drag, ou à precipitação induzida por deformação do Nb, Prec.

- Tamanho de grão médio da austenita, D Mean. 
- Tamanho de grão crítico, $D c(0.1)$, que corresponde ao valor abaixo do qual estão compreendidos $90 \%$ dos tamanhos de grãos da distribuição. Esse parâmetro pode ser considerado uma medida de grau de heterogeneidade da microestrutura.

- Tamanho de grão máximo da austenita, $D$ Max.

- A razão entre $D$ Max/D Mean, dado por $Z$.

- A deformação acumulada na microestrutura.

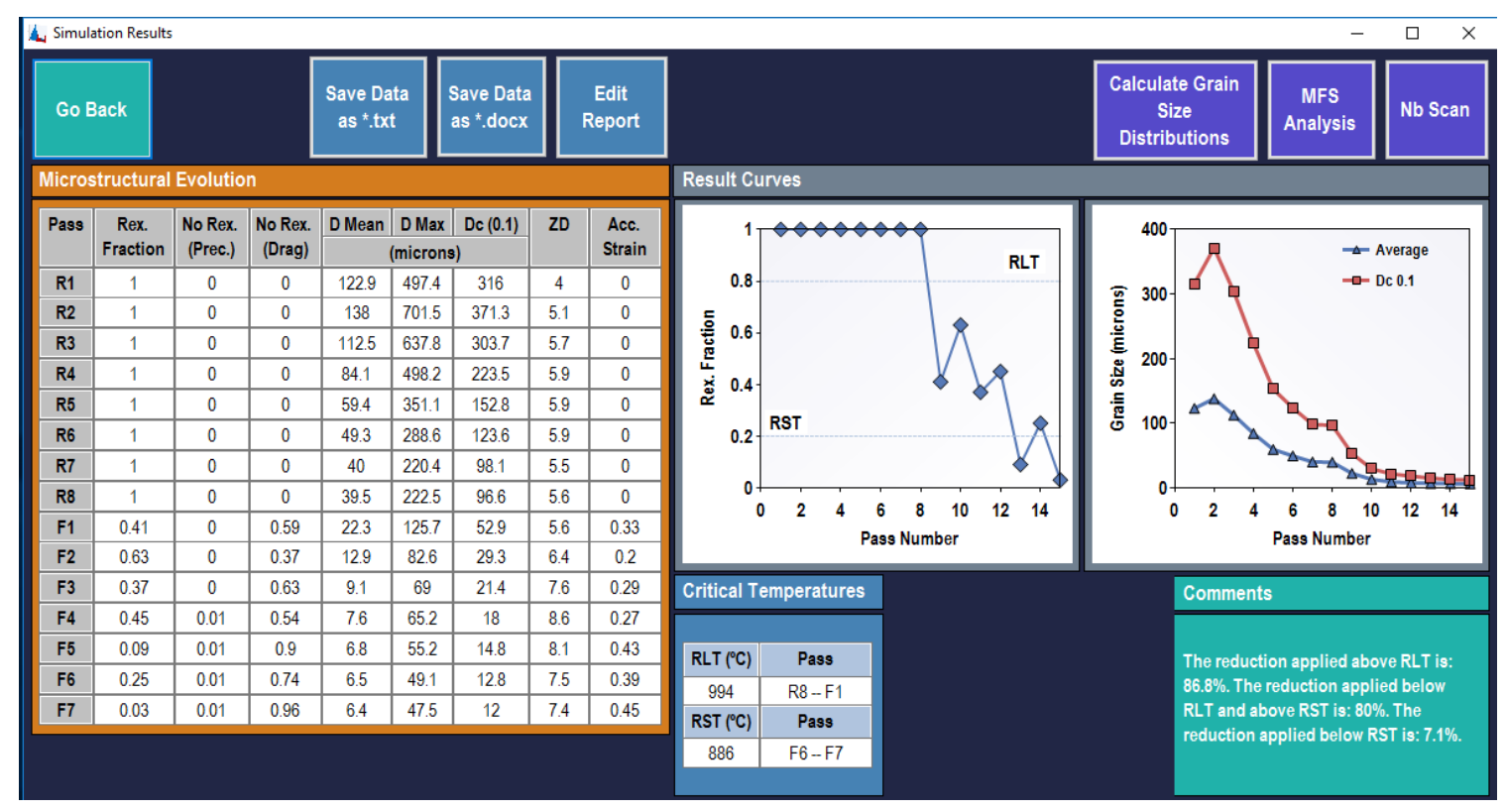

Figura 3.Resultados calculados pelo modelo considerando a condição original de processamento.

Os dois diagramas contidos na Figura 3 permitem a visualização da evolução da fração recristalizada e do tamanho de grão de austenita previstos durante 0 processo.

Quanto ao comportamento da microestrutura durante a laminação, o modelo permite também visualizar a distribuição dos tamanhos de grão da austenita previstos após cada passe. A Figura 4 mostra a tela com as previsões considerando também 0 caso original.

A Figura 5 mostra os valores calculados das tensões médias de escoamento, TME, ou meanflow stress, MFS, em inglês, durante a laminação. Os valores das reduções aplicadas no processo juntamente com a temperatura e a composição química do material, são os fatores mais importantes que definem o comportamento dos mecanismos de amaciamento e de endurecimento, e assim das cargas de laminação, durante o processo de laminação a quente ${ }^{[4]}$. 


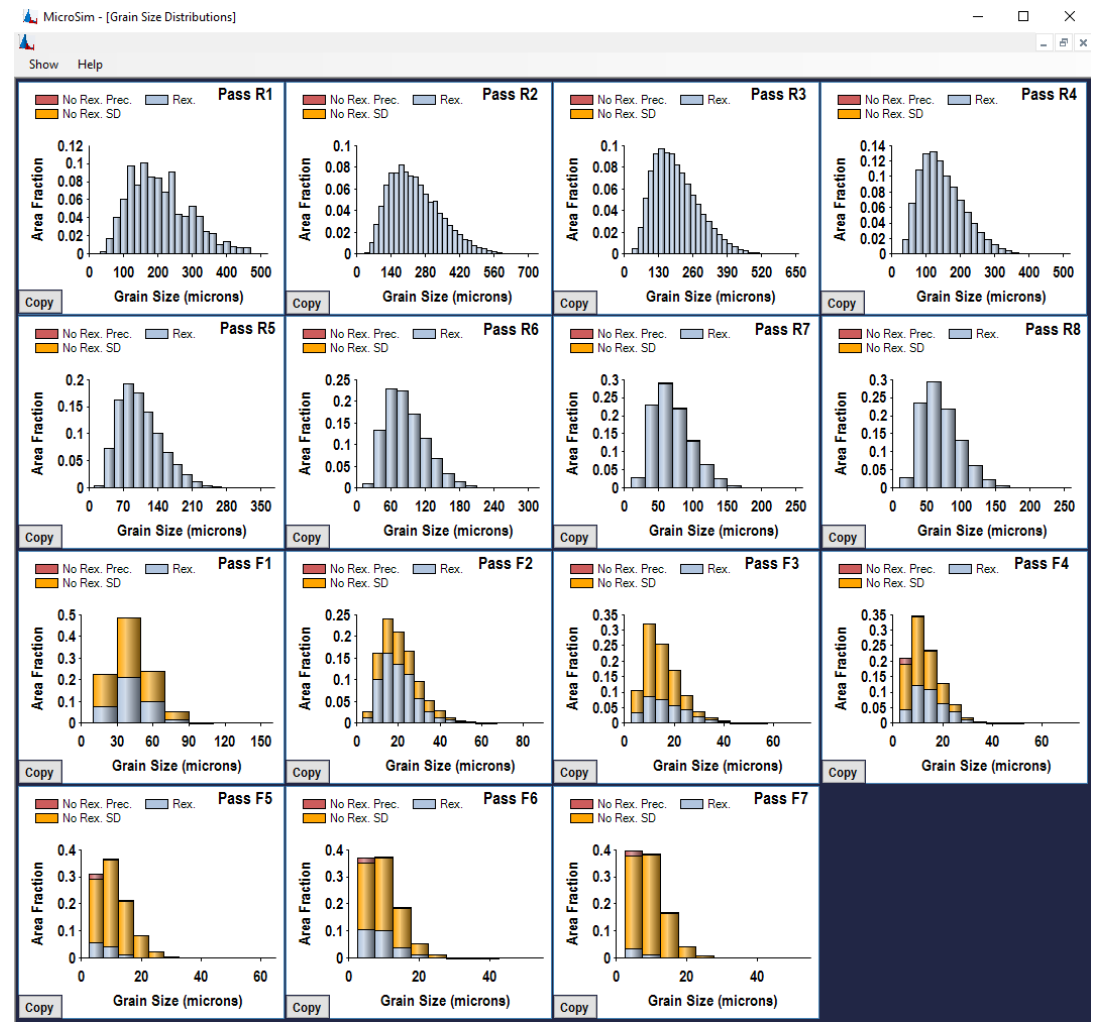

Figura 4. Distribuição de tamanhos de grãos da austenita após cada passe de laminação calculadas para a condição original.

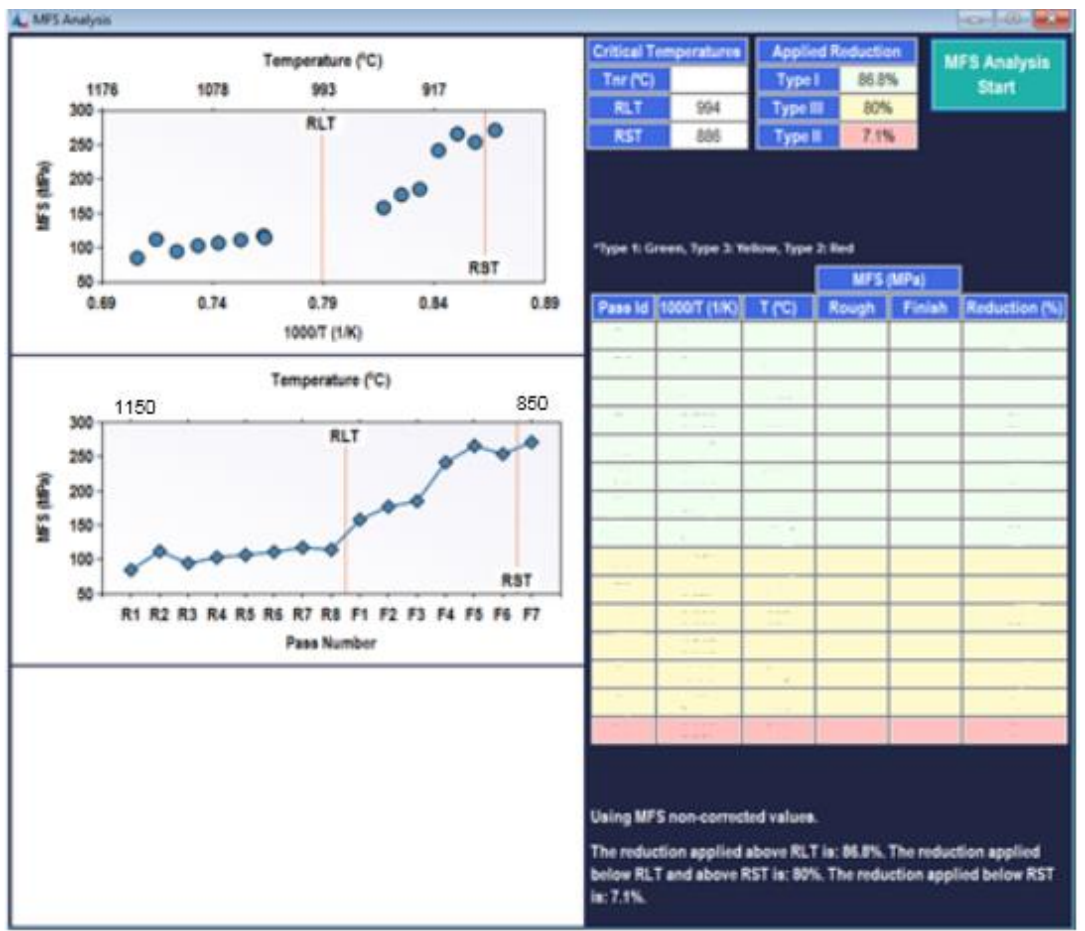

Figura 5.Valores das tensões médias de escoamento, TME ou MFS, calculadas e do perfil de deformação utilizado no processo.

\section{Comparações com condições modificadas}

Uma vez previsto o comportamento da microestrutura para as condições originais de processamento, o modelo foi novamente rodado considerando a modificação da 
temperatura de reaquecimento da placa. As temperaturas de desbaste também sofreram uma redução proporcional. As temperaturas de acabamento, no entando, permaneceram praticamente as mesmas, uma vez que o tempo de transferência foi reduzido. A Figura 6 mostra a comparação entre os valores das frações recristalizadas e das deformações acumuladas calculadas para as duas condições.

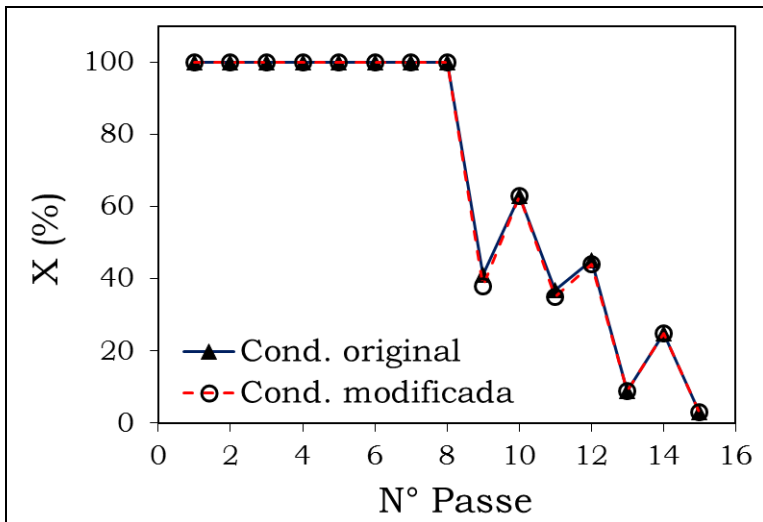

(a)

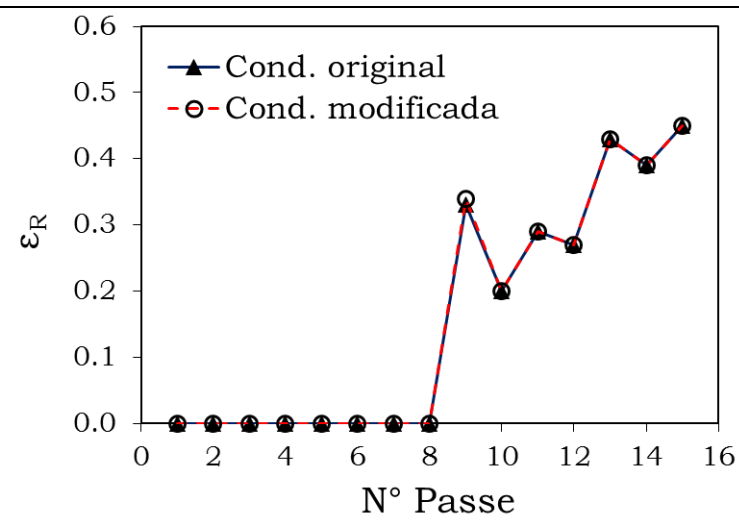

(b)

Figura 6. Comparação entre os valores calculados pelo modelo após cada passe das (a) frações recristalizadas, e (b) deformações acumuladas.

Os valores calculados das frações recristalizadas e das deformações acumuladas foram os mesmos, mostrando que o comportamento da microestrutura do material não seria influenciado pelas alterações realizadas. Mesmo com as diferenças de temperaturas durante o desbaste, a sequência de deformações dessa etapa da laminação seria capaz de levar à mesma condição dos tamanhos de grãos de austenita. Já durante o acabamento, com as temperaturas sendo praticamente as mesmas, a distribuição resultante também foi praticamente a mesma.

O mesmo comportamento foi previsto para as distribuições dos tamanhos de grão de austenita, mostrados na Figura 7, na saída no desbaste (a), e na saída do acabamento antes do resfriamento (b).

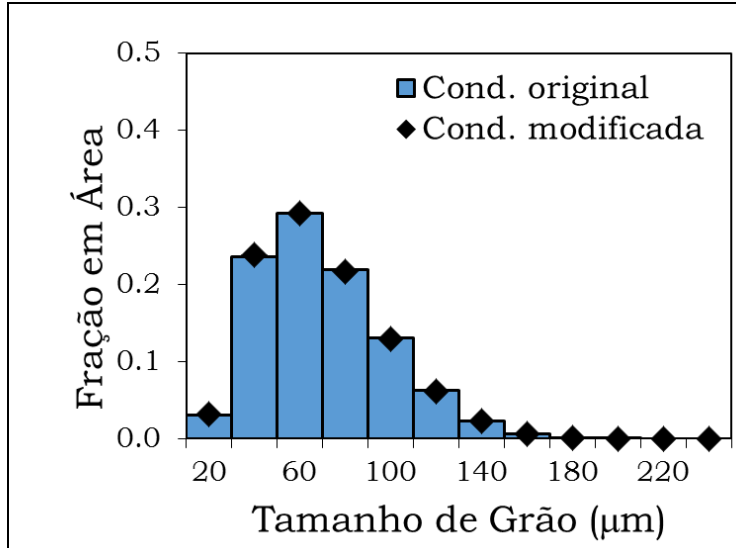

(a)

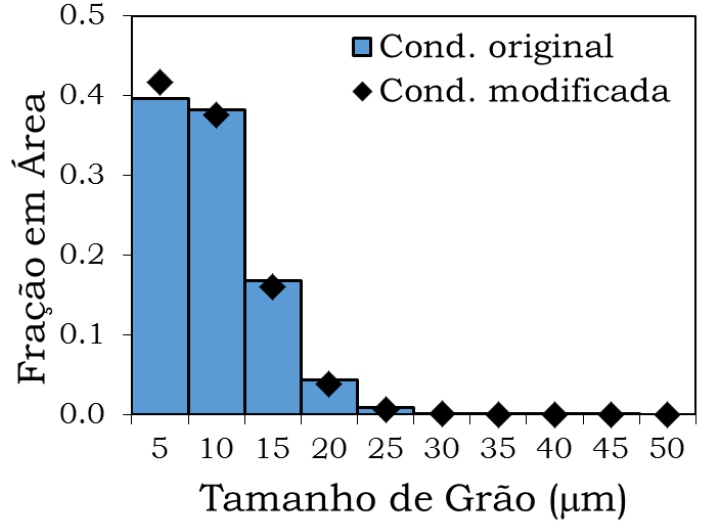

(b)

Figura 7. Distribuição dos tamanhos de grãos de austenita calculadas pelo modelo, (a) ao fim do desbaste, (b) ao fim do acabamento. 
Para validar os resultados mostrados acima, medições dos tamanhos de grãos de ferrita foram realizadas para o material obtido via laminação sob a condição normal, e para o material obtido sob a condição modificada. A Figura 8 mostra as microestruturas do material laminado nas duas condições. As microestruturas foram obtidas sob a mesma condição de resfriamento, citada acima

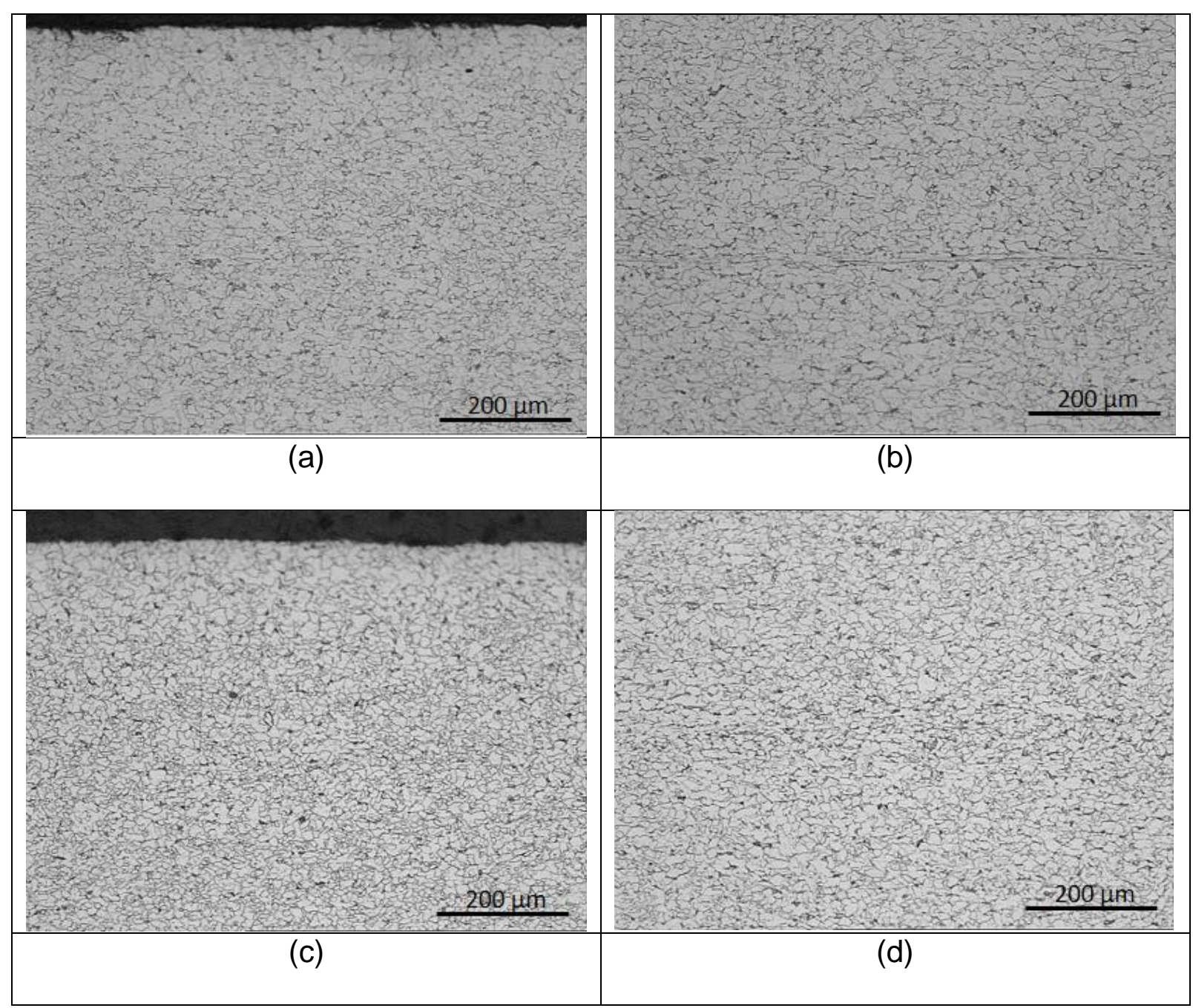

Figura 8. Caracterização dos grãos de ferrita (a) na superficie e (b) no centro do material laminado sob as condições originais, e (c) na superficie e (d) no centro do material laminado sob as condições modificadas.

Dessa forma, a mudança da temperatura de reaquecimento não influenciaria a microestrutura obtida de laminação. Consequentemente, esta alteração pode levar à obtenção do mesmo produto com possibilidades de melhor produtividade. Ademais, o modelo aqui apresentado mostrou ser capaz de prever a microestrutura de um produto de LTQ em termos da distribuição dos tamanhos de grãos de austenita e da tensão média de escoamento durante o processo. O estudo deste comportamento, além de levar a um conhecimento mais profundo do estado do material, pode permitir melhorias no processo e a previsão de parâmetros fundamentais no desenho de uma laminação, como por exemplo estimar as cargas de laminação, o que compreenderá as próximas etapas deste projeto. 


\section{CONCLUSÃo}

O modelo desenvolvido e apresentado neste trabalho mostrou-se capaz de prever a microestrutura obtida de laminação em termos da sua distribuição de tamanhos de grão e do comportamento da tensão média de escoamento durante o processo.

A redução da temperatura de reaquecimento não teve impacto negativo na microestrutura obtida da laminação.

\section{AGRADECIMENTOS}

Os autores gostariam de agradecer a CSN, a CBMM e o CEIT pelo apoio no desenvolvimento deste trabalho.

\section{REFERÊNCIAS}

1 Silva M.G., Barbosa R., Carvalho C.R.G., Bastos F., Ferreira J.L.G., Rebellato M.A., Hauegen C.G. Avaliação dos Parâmetros do Processo Termomecânico da Laminação de Tiras a Quente de Aços Microligados ao Nióbio.In ABM Week 2015: $52^{\circ}$ seminário de laminação. Rio de Janeiro, Brasil. 2015.

2 Uranga P., Fernandéz A.I., López B., Ibabe J.M.R. Modeling of Austenite Grain Size Distribution in $\mathrm{Nb}$ Microalloyed Steels Processed by Thin Slab Casting and Direct Rolling (TSDR) Route, ISIJ International, v. 44, n. 8, p. 1416-1425. mai. 2004.

3 Uranga P., Ibabe J.R., Stalheim D.G., Barbosa R., Rebellato M. Application of Practical Modeling of Microalloyed Steels for Improved Metallurgy, Productivity and Cost Reduction in Hot Strip Mill Applications. In AISTech: The Iron \& Steel Technology Conference and Exposition. Pittsburgh, USA. 2016.

4 Stalheim D.G., Barbosa R., Bastos F.Basic Metallurgy/Processing Design Concepts for Optimized Hot Strip Structural Steels in Yield Strengths from 300-700 MPa. In ABM Week 2016: 53 seminário de laminação. Rio de Janeiro, Brasil. 2016. 